\title{
Water Soluble PEGylated phenothiazines. Synthesis, Characterization and Antitumor Properties ${ }^{\dagger}$
}

\author{
Sandu Cibotaru ${ }^{1}$, Andreea-Isabela Sandu ${ }^{1}$, Dalila Belei ${ }^{2}$ and Luminita Marin ${ }^{1}$ \\ 1 "Petru Poni" Institute of Macromolecular Chemistry of Romanian Academy, Iasi, Romania \\ cibotaru.sandu@icmpp.ro \\ 2 “Alexandru Ioan Cuza" University, Department of Organic Chemistry, Iasi, Romania dalila@uaic.ro \\ Correspondence: cibotaru.sandu@icmpp.ro \\ + Presented at the First International Conference on “Green" Polymer Materials 2020, 5-25 November 2020; \\ Available online: https://cgpm2020.sciforum.net/.
}

Published: 4 November 2020

\begin{abstract}
The paper reports a series of three new PEGylated phenothiazine derivatives which keep the potential of valuable building blocks for preparing bio-materials. PEGylated phenothiazine derivatives were prepared by grafting PEG chains to the phenothiazine core by three different linkers: ether, ester or amide units. The structure of the targeted molecules was confirmed by FTIR and NMR spectra. The capacity of the synthetized compounds to self-assembly in water was studied by DLS and UV-vis techniques, which allowed finding the hydrodynamic diameter of the aggregates. The particularities of the formed aggregates were investigated by fluorescence spectroscopy, SEM, AFM, POM and UV light microscopy. Their biocompatibility was assessed on normal human dermal fibroblasts and five human cancer cell lines. The synthetized compounds showed the formation of luminescent aggregates which proved excellent biocompatibility on normal cells. A concentration dependent cytotoxicity against HeLa cancer cell lines was noticed for the PEGylated phenothiazine containing an ester unit and for direct PEGylated phenothiazine.
\end{abstract}

Keywords: phenothiazine; poly(ethylene glycol); luminescence; biocompatibility; antitumor activity

\section{Introduction}

Phenothiazine is a valuable building block for the sinthesys of a wide range of compounds used in bio-medicine. Besides their neuroleptic activitie [1], phenothiazines are used in the synthesis of many classes of drugs, such as bactericides, fungicides, antitumor, antiviral, anti-inflamatory, antimalarial, antifilarial, trypanocidal, anticonvulsant, analgesic and immunosuppressive agnts [2]. In cancer treatment, phenothiazine based derivatives presented promising results as adjuvants and as inhibitors of Farnesyltransferase [3], Tubulin polymerization [4], etc.

Because of their low solubility in water, the biological activity of phenothiazine based drugs is limited[5]. Up to now, phenothiazine derivatives used in cancer treatment were administrated as ammonium salts to be water soluble [6]. However, besides the citoxity against cancer cells, the citoxity against normal cells wasn't declare.

In this work our attention was focused on sinthesys of three new phenothiazine derivatives by grafting a poly(ethylene glycol) chain at the nitrogen atom of phenothiazie core, using three different sinthesys strategies to obtain biocompatible, low toxic and water soluble phenothiazine derivatives. The poly(ethylene glycol) unit was chosen because it is a water soluble, biocompatible FDA approved synthetic polymer, frequently used in bioaplication, especialy for drug formulation [7]. The new synthesized derivatives showed an amphyphylic behavior, due to their hydrophobic-hydrophylic 
designe. Their aggregation ability and time stability was studed and biological activity on normal and cancer cells.

\section{Experiments}

\subsection{Materials and Methods}

\subsubsection{Synthesis}

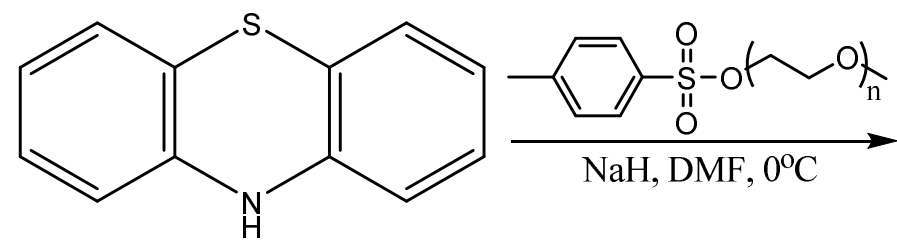<smiles>CCOCCOCCN1c2ccccc2Sc2ccccc21</smiles><smiles>c1ccc2c(c1)Nc1ccccc1S2</smiles>

1. $\mathrm{NaH}, \mathrm{DMF}, 0^{\circ} \mathrm{C}$<smiles>CCOC(=O)CBr</smiles>
2. a) $\mathrm{NaOH}, \mathrm{MeOH} 60^{\circ} \mathrm{C}$ b) $\mathrm{HCl}$ 3. DMAP, DCC tO $\mathrm{X}_{\mathrm{n}}$<smiles>COCCOC(=O)CN1c2ccccc2Sc2ccccc21</smiles><smiles>c1ccc2c(c1)Nc1ccccc1S2</smiles>

1. $\mathrm{NaH}, \mathrm{DMF}, 0^{\circ} \mathrm{C}$<smiles>CCOC(=O)CBr</smiles>

2. a) $\mathrm{NaOH}, \mathrm{MeOH} 60^{\circ} \mathrm{C}$ b) $\mathrm{HCl}$

3. NHS, EDC, DCM

4. TEA, DCM, $+\mathrm{O}+\mathrm{NH}_{2}$<smiles>CC(C)OCCNC(=O)CN1c2ccccc2Sc2ccccc21</smiles>

Scheme 1. Synthesis of the PEGylated derivatives.

\section{Results}

\subsection{Synthesis}

Three PTZ derivatives were obtained using three different synthetic routes. The first derivative was obtained by direct alkylation of a tosylated poly(ethylene glycol)PEG chain resulting the (PP) compound. The other two were synthesized by grafting the PEG chain via an ester function (PPO), and an amide function (PPN), respectively (Scheme 1).

The successful synthesis of the compounds was confirmed by FTIR and NMR spectroscopy. The FTIR spectra (Fig. 1a) displayed the characteristic vibrations of the main groups present in the final 
compounds. The NMR spectra (Figure $1 \mathrm{~b}$ ) showed the disappearance of the chemical shifting characteristic to the hydrogen linked to the nitrogen atom of phenothiazine, and chemical shifting characteristic to the new synthesized compounds in the right ratio of their integrals.

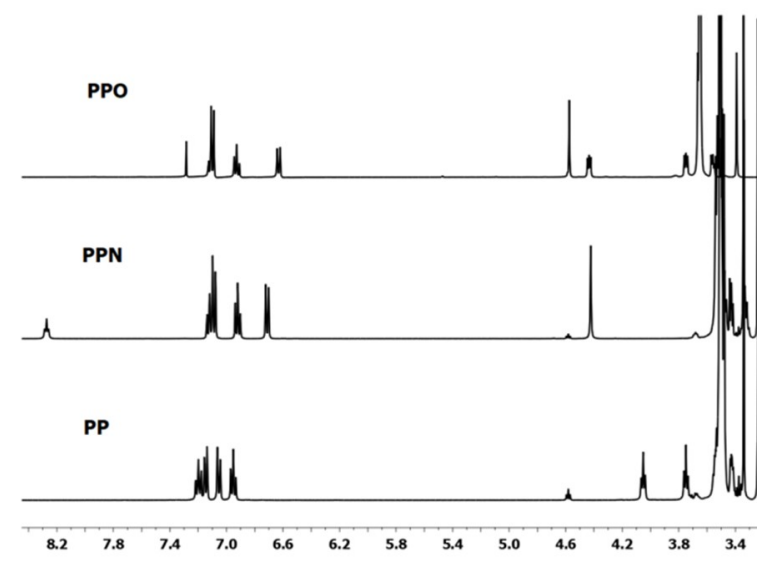

(a)

(b)

Figure 1. (a) FTIR spectra of the PEGylated phenothiazine derivatives, (b) ${ }^{1} \mathrm{H}$ NMR spectra of the PEGylated derivatives.

\subsection{Photophysical Behavior}

The photophysical behavior of the compounds was investigated by UV-vis spectroscopy in comparison with the pristine PTZ. The compounds absorption spectra (Figure 2a) showed the two absorption bands from phenothiazine, with the difference that the second one is bathochromic shifted with $25 \mathrm{~nm}$. This is a consequence of aggregate formation, due to the amphiphilic nature of the compounds.

On the other side, the samples were able to emit blue light under UV lamp illumination (Figure $3 \mathrm{~d}$ ). The recorded emission spectra (Figure $3 \mathrm{~b}$ ) confirmed the visual observations by the presence in the spectra of a band with a maximum in the blue region at $450 \mathrm{~nm}$.

(a)

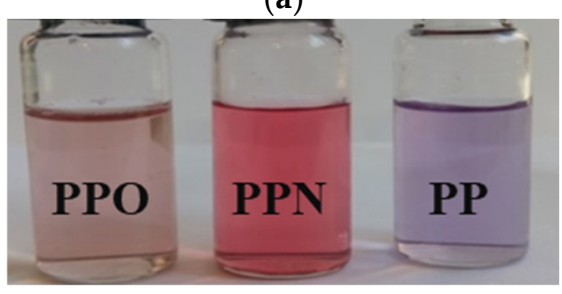

(c) (b)

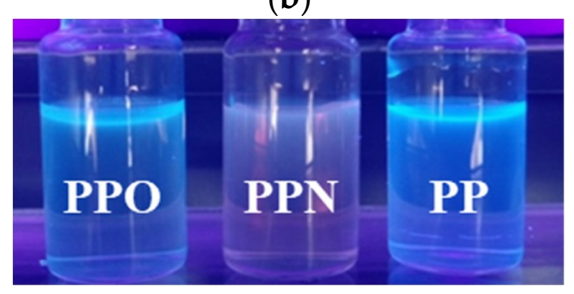

(d) 
Figure 2. (a) UV-vis absorption spectra of PEGylated compounds and PTZ and (b) photoluminescence spectra of PEGylated compounds in water. Compounds water solution under (c) natural light and (d) UV light.

\subsection{Self-assembling Behavior}

The UV-vis findings, according to which the compounds are able to self assemble into aggregates, were confirmed by DLS (Figure 3) measurements.

In all cases the aggregates were nanometric with a mean diameter of $200 \mathrm{~nm}$ and a quite low dimensional polydispersity. The morphological investigations by SEM, AFM and POM techniques (Figure 4), demonstrated the spherical shape of the aggregates and their uniformity.

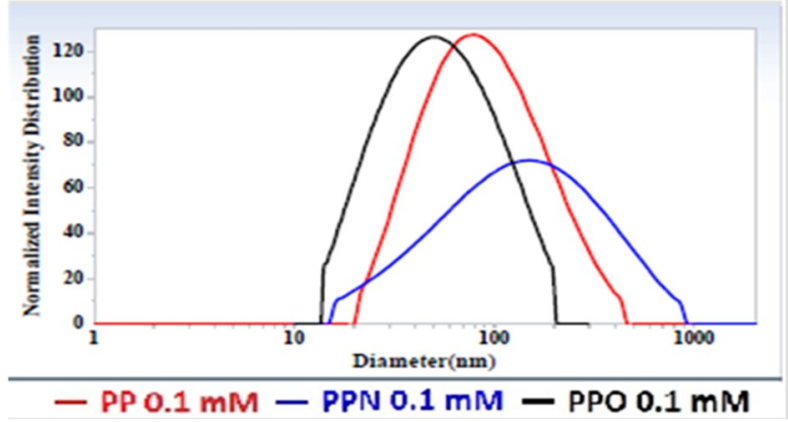

Figure 3. DLS graphs of the studied compounds.

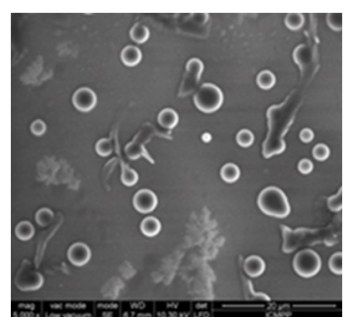

(a)

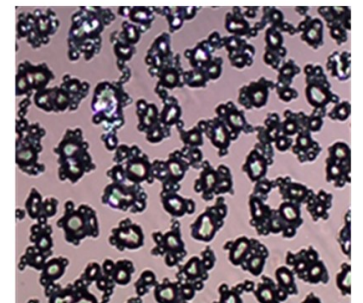

(b)

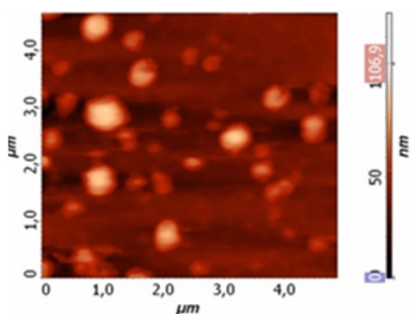

(c)

Figure 4. (a) SEM (b) POM images of the PP embedded into a solid PVAB matrix and (c)AFM images of the PP in pure form.

\subsection{In vitro Biocompatibility}

All three compounds presented a good biocompatibility on Normal Human Dermal Fibroblast (NHDF) cells for concentrations up to $0.1 \mathrm{mM}$, while for PPN the concentration increased up to $1 \mathrm{mM}$ (Figure 5).

The PP and PPO presented a good antitumor activity on Human Cervical Cancer (HeLa) cells at concentration $0.1 \mathrm{mM}$, with a relative cell viability of $58 \%$ for PP and $34 \%$ for PPO (Figure 5). 

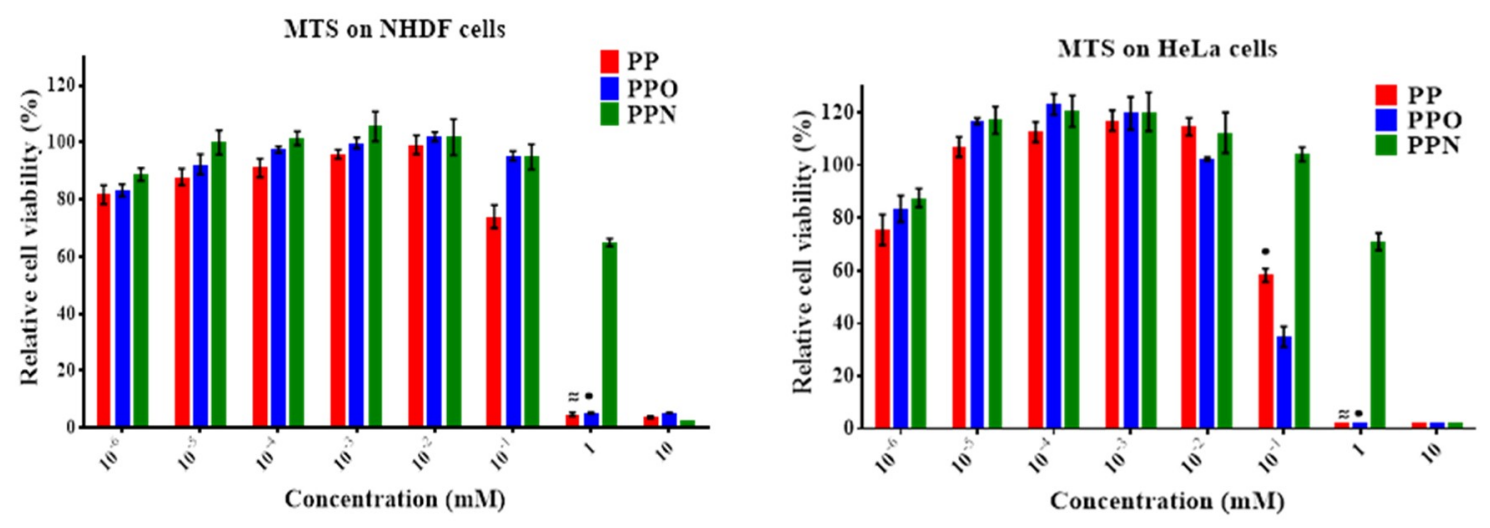

Figure 5. Cell viability on NHDF and HeLa cells.

Acknowledgments: This work was supported by a project financed through a Romanian National Authority for Scientific Research MEN - UEFISCDI, grant project PN-III-P4-ID-PCCF-2016-0050References

\section{References}

1. M.M.Dougherty, J.M. Marraffa, Phenothiazines, Encyclopedia of Toxicology, 2014, $881-883$. DOI:10.1016/B978-0-12-386454-3.00769-7

2. Varga, Á. Csonka, A Csonka, J Molnár, L. Amaral, G. Spengler, Possible biological and clinical applications of phenothiazines, Anticancer Res. 2017 37(11), 5983-5993, DOI:10.21873/invivo.11746

3. D.Belei,C. Dumea, A. Samson, A. Farce, J. Dubois, E. Bîcu, A. Ghinet, New farnesyltransferase inhibitors in the phenothiazine series, Bioorg. Med. Chem. Lett. 2012, 22, 4517-4522. DOI:10.1016/j.bmcl.2012.06.007

4. H. Prinz, B. Chamasmani, K. Vogel, K. J. Bohm, B. Aicher, M. Gerlach,E. G. Gunther, P. Amon, I. Ivanov, K. Muller, N-Benzoylated Phenoxazines and Phenothiazines: Synthesis, Antiproliferative Activity, and Inhibition of Tubulin Polymerization, J. Med. Chem. 2011, 54, 4247-4263. DOI:10.1021/jm200436t

5. U. Domanska, A. Pelczarska, A. Pobudkowska, Solubility and pKa determination of six structurally related phenothiazines, Int. J. Pharm. 2011, 421, 135-144, DOI: 10.1016/j.ijpharm.2011.09.040

6. K. Pluta, M. Jeleń, B. Morak-Młodawska, M. Zimecki, J. Artym, M. Kocięba, E. Zaczyńska, Azaphenothiazines - promising phenothiazine derivatives. An insight into nomenclature, synthesis, structure elucidation and biological properties, Eur. J. Med. Chem. 2017, 138, 774-806. DOI:10.1016/j.ejmech.2017.07.009

7. M. Zamani, M. Aghajanzadeh, K. Rostamizadeh, H. Kheiri Manjili, M. Fridoni,H. Danafar, In vivo study of poly (ethylene glycol)-poly (caprolactone)-modified folic acid nanocarriers as a $\mathrm{pH}$ responsive system for tumor-targeted co-delivery of tamoxifen and quercetin, J Drug Deliv Sci Technol 2019, 54, 101283.

Publisher's Note: MDPI stays neutral with regard to jurisdictional claims in published maps and institutional affiliations.

(C) 2020 by the authors; licensee MDPI, Basel, Switzerland. This article is an open access article distributed under

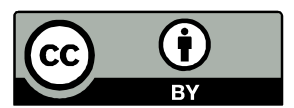
the terms and conditions of the Creative Commons by Attribution (CC-BY) license (http://creativecommons.org/licenses/by/4.0/). 